\title{
Acariciar una imagen. Mímesis desviada de la imagen corporal como forma de subversión frente a un poder biopolítico
}

\author{
To carress an image. Deflecting mimesis of body image as a \\ subversive form to confront biopolitics
}

RAQUEL ASENSI BLANCO*

\begin{abstract}
Resumen: El interés principal de este trabajo se centra en diversas prácticas artísticas subversivas relacionadas con la imagen corporal y la identidad, que se enfrentan a la imagen de un otro, en base a su 'semejanza' o 'diferencia'. Analizamos casos como el colectivo Pussy Riot en Russia, el caso de Amina en FEMEN, o un caso local a través de la comparsa Pinpilinpauxa. El trabajo está ligado a la producción de un trabajo artístico que plantea algunos problemas que derivan de la construcción de la identidad. El 'oxímoron' nos ha servido como herramienta para clasificar el contenido de la investigación rompiendo con la forma clásica occidental de dividir la realidad en pares de conceptos opuestos.

Palabras clave: Imagen, mímesis, identidad, performatividad, arte.
\end{abstract}

\begin{abstract}
The main interest of this work is based on several subversive artistic practices which use body images and the concept of identity, confronted with the image of an Other, related to it by 'ressemblance' or 'difference'. We analise cases like the Pussy Riot collective in Russia, Amina's case in FEMEN, or a local case, Pinpilinpauxa. This work is closely related to the production of an artistic body of work which contemplates some of the problems that derive from the social construction identity. 'Oxímoron' is a conceptual tool we have used to classify the content, disrupting the western tradition of dividing reality into opposite concepts.
\end{abstract}

Keywords: Image, mimesis, identity, performativity, art.

Podemos mirar el Arte como un conjunto de prácticas aceptadas en el ámbito público, generalmente por las instituciones. También podemos tener un punto de vista intersubjetivo que se relacione con aquella heterotopologíal, que llamaba Michel Foucault al estudio de esos lugares que normalmente pasan desapercibidos.

Nos interesan diversas prácticas artísticas que se basan en la imagen corporal, imagen que está íntimamente ligada a la identidad, desviándola como forma de subversión ante un poder que se inmiscuye en los aspectos de la vida privada y pública; de la salud, de la

Fecha de recepción: 10/06/2016. Fecha de aceptación: 27/07/2016.

* Universidad del País Vasco - Euskal Herriko Unibertsitatea, Estudiante de Doctorado en Arte Contemporáneo, Departamento de Escultura, Línea de Creación como Investigación.

1 CALDERON, P. (2003); Foucault par lui-meme 
higiene, de la natalidad, la longevidad, la familia, lo que Foucault llamó el poder biopolítico². Interpretamos por ello teorías que se relacionan con esta idea de la semejanza, de mímesis, frente a la diferencia, o mímesis desviada.

Los individuos y los grupos ya no reproducen tradiciones sino que, "improvisan realizaciones locales a partir de pasados (re)coleccionados, recurriendo a medios, símbolos, lenguajes extranjeros. La identidad es coyuntural, no esencial" ". Los límites entre oriente y occidente, entre culturas y géneros se han homogeneizado y mestizado en una sociedad interconectada y globalizada. La supuesta semejanza y diferencia que constituían identidades individualizadas y destacadas se deshace. Tal vez por eso es el ambiente propicio para prácticas que rompen con la repetición, la reiteración, la similitud, y proponen aperturas a una grieta, al cambio.

Esto nos permitió repensar el concepto de mímesis y la dicotomía clásica. Proponemos como contrapartida el juego en la forma poética del oxímoron, titulando algunos temas de esta manera; Mímesis desviada, Rizoma capitalista, Histeria bella, Coraza frágil, Identidad nómada. El oxímoron, dentro de las figuras literarias en retórica, es una figura que consiste en usar dos conceptos de significado opuesto en una sola expresión, generando un tercer concepto, forzando al lector a comprender el sentido metafórico.

El trabajo está ligado a la producción de un trabajo artístico que plantea algunos problemas de la construcción social de la identidad por medio de imágenes corporales. Las piezas creadas miran al mundo no como un todo dividido en pares de opuestos, sino como decía Haraway, un agente irónico lleno de perplejidades y paradojas 4 .

\section{Mímesis desviada}

"El mimetismo es un mal concepto, producto de una lógica binaria, para explicar fenómenos que tienen otra naturaleza." 5

Revisando el concepto de mímesis observamos como se convirtió en una cuestión fundamental en el pensamiento clásico, donde adquirió gran importancia en la educación. De esta manera se aseguraban que los niños aprendieran a actuar correctamente, aprendieran del orden y la medida, que conforme a la naturaleza hallaran la importancia de encontrar las semejanzas, la lógica del sentido, la lógica de lo Mismo. A través de esta imitación se logra que los futuros hombres y mujeres encarnen el orden que se ha predispuesto anterior a su existencia y a su experiencia.

Durante el siglo XX podemos observar la necesidad de perpetuar la mesura y la medida en autores estructuralistas. En la obra de Jacques Lacan el hombre llega a lo social a través

2 FOUCAULT, M., (2005); Historia de la sexualidad 1. La voluntad de saber, trad. Ulises Guiñazú, Madrid, Siglo XXI DE ESPAÑA EDITORES, Ed. original; (1976) Histoire de la sexualité. 1. La volonté de savoir, Editions Gallimard, Paris.

3 GEERTZ, Clifford (1994); Conocimiento local,, Paidós ibérica S.A., Barcelona. Ed. original: (1983) Local Knowledge, Further essays in interpretative anthropology. Basic Books Inc.

4 J. HARAWAY, Donna (1995): Ciencia, cyborgs y mujeres, Ediciones Cátedra S.A., Madrid. Ed. original: (1991) Simians, Cyborgs and Women. The Reinvention of Nature, Free Asociation Books, Ltd., London

5 DELEUZE, Gilles; GUATTARI, Félix, RIZOMA Introducción (2013), trad. José Vazquez Pérez y Umbelina Larraceleta, Valencia, pp. 17-28. Ed. original: (1977) Rhizome (Introduction), Editions de Minuit, París. 
de cierta imagen de sí mismo, una imago que es exterior a él, a la vez que familiar y extraña. Lo que Lacan llamaba yo ideal ${ }^{6}$ se forma, se construye, en relación a la identificación y/o diferenciación ante esas imágenes, y finalmente con la imagen propia del cuerpo reflejada exteriormente. Esa primera imagen corporal identitaria es afectada, moldeada, transformada, a través de las miradas de otros ya existentes y de sus imágenes, en especial, de la imagen paterna que servirá de ideal.

Luce Irigaray, discípula de Lacan, habló sobre el punto ciego de la teoría psicoanalítica. La perpetuación de la semejanza, impide ver aquello que existe y es diferente, en este caso la mujer, dice, “...si, le propusiéramos identificar a otro(a) llegaría sin duda a confesarnos que no ve, que ya no ve, muy bien. Que hay que esperar un poco para que pueda evaluar, estimar en su medida, aquello con lo que, aquel con el que, tiene que habérselas. ¿El tiempo necesario para acostumbrar su mirada a lo que tiene ante él? ¿O para que este <<objeto>> entre en su perspectiva? "7. Las teorías feministas, en este caso la de la diferencia, comenzaron a abrir nuestras miradas ante realidades que antes, tal vez por silenciosas no habían existido.

En los años '80 Judith Butler propone como teoría y herramienta ideológica la identidad de género como una construcción social. Cuestiona su supuesta naturalidad y propone ante esta imposición mimética un juego que desvía ese reflejo, lo que llama mímesis desviada ${ }^{8}$.

Para Austin, los actos de habla en general se podían dividir en los actos ilocucionarios y perlocucionarios ${ }^{9}$. En los primeros, las palabras hacen lo que dicen, en los segundos, causan efectos. El carácter principal de los enunciados es que no son inocentes palabras, tienen poder para arrinconar, apalear, esconder, quemar, apagar, también de ensalzar, relativizar, empoderar, liberar.

Los enunciados nos designan un lugar por el color de nuestra piel y por nuestro sexo al nacer. Las reglas o normas del lenguaje, como el género (mujer-hombre), se fijan a través de la repetición performativa que las constituye como "naturales" y "necesarias", “... una existencia social del cuerpo se hace posible gracias a su interpelación en términos de lenguaje" 10 . Existimos, somos, uno frente al otro, gracias a esta interpelación lingüística. Esto significa que nuestra naturaleza es social. Hay casos en los que se desvía este reflejo, formando parte de un juego entre lo que podemos y lo que queremos, entre la voluntad y el poder.

\section{Coraza Frágil}

Si pensamos en un niño que creciera durante el régimen Franquista en España, forzado por la represión y la censura de tantísimas imágenes, sus referentes para la construcción de una imagen propia serían escasos. El signo del padre soberano y la imagen de la madre

6 LACAN, Jacques, (1972-1973); Los Seminarios de Jacques Lacan / Seminario 20. Aún (08/08/2015). Edición electrónica, URL: <https://agapepsicoanalitico.files.wordpress.com/>

7 IRIGARAY, Luce (2007); Espéculo de la otra mujer,, Ediciones Akal, S.A., Madrid. Ed. original: (1974) Speculum de l'autre femme, Les Éditions de Minuit, París.

8 BUTLER, Judith (2004); Lenguaje, poder e identidad, Vallehermoso, Síntesis S.A.

9 AUSTIN, J.L. (1955); Como hacer cosas con palabras, Edición electrónica. URL: < $\underline{w w w . p h i l o s o p h i a . c l />~}$ Escuela de Filosofía Universidad ARCIS, pp. 110.

10 BUTLER, Judith. (2004); Lenguaje, poder e identidad,, Vallehermoso, Síntesis S.A. 
objeto podrían ser lo máximo a lo que aspirar en ese tránsito hacia la identidad propia. En la mayoría de los casos, aun creciendo en un ambiente de transición hacia mayores libertades en lo que respecta a la sexualidad, al cuerpo, a la igualdad de oportunidades, se han repetido y han encarnado los mismos símbolos que constituían a la familia española del franquismo.

En los años de la transición, comenzaron a aparecer revistas valientes, como "Vindicación feminista" 11 , que hacían aparecer imágenes hasta entonces ocultas. El poder lo sabe y por ello censura, las imágenes son performativas como los enunciados, incluso un poco más complejas, porque son misteriosas, abiertas a interpretaciones continuas.

\section{Un caso local: la comparsa Pinpilinpauxa}

Durante el año '78 se comenzaron a lanzar propuestas a través de un concurso de ideas para las fiestas de Bilbao, acompañado por la formación de comparsas. Sería la primera vez que el pueblo podía organizarse y participar activamente en las fiestas. Durante el franquismo las fiestas habían consistido en funciones de teatro y espectáculos taurinos para los que se lo podían permitir, habitualmente los pertenecientes a la clase burguesa bilbaína.

Las actividades que se propusieron en aquel año son las mismas que podemos ver cada año en las calles de Bilbao. La bajada de las comparsas, los concursos gastronómicos, las "txosnas", los espectáculos, el toro de fuego, la música y el espectáculo rodeado de bebida y comida.

Los pertenecientes al grupo que fundó "Pinpilinpauxa" pertenecían en mayor o menor medida a dos asociaciones u organizaciones que ya existían por aquel entonces, COPEL y EHGAM. La primera era la Coordinadora de Presos Españoles en Lucha, y la segunda, Euskal Herriko Gays-Les Askapen Mugimendua. La idea principal de la comparsa era la no afiliación a ningún partido político, ningún grupo organizado y jerárquico. Lo importante sería entonces festejar esta novedosa sensación de libertad y de trasfondo se destinarían fondos para los presos sociales, comunes, y la asociación de gays y lesbianas.

Presos sociales es donde se enmarcaba a las personas encarceladas por su condición sexual durante el franquismo. Eran criminalizados bajo la "ley de peligrosidad y rehabilitación social"12 aprobada por el régimen franquista en 1970, que sustituía a la "ley de vagos y maleantes" para el control de los individuos considerados antisociales. Las penas resultaban en el pago de multas o penas de hasta cinco años de internamiento en cárceles o centros psiquiátricos para la rehabilitación de los individuos.

Había estado velado el tema de los presos sociales por condición sexual, pero algunos relatan historias sobre como algunos/as habían sido detenidos/as sin causa aparente bajo la "Ley de Vagos y Maleantes".

Los fundadores de la comparsa repiten la importancia que tuvo el hecho de que se juntaran alrededor de la comparsa personalidades de todo tipo de clase social, de ideología política, con ideas creativas que generaban una explosión de libertad a su alrededor. Compañeros de otras comparsas llegaron a decir de ellos que eran los "intelectuales y homosexuales". Querían significar elegancia e intelectualidad junto con esa idea de libertad.

11 A. LARUMBE GURRAITZ, M. A. (1976-1979); VINDICACIÓN FEMINISTA: Una voz colectiva, una historia propia. Antología facsímil de textos, Prensa Universitaria de Zaragoza. Cat. Feminismos.

12 LACOMUNA, La ley de peligrosidad social y la represión franquista, URL: <http://www.lacomunapresxsdelfranquismo.org/2012/02/08/la-ley-de-peligrosidad-social-y-la-represion-franquista/>, 08/02/2012 
Liberación corporal que se veía a través de las imágenes del cuerpo que mostraban que durante tanto tiempo había sido prohibido señalar. Eran imágenes que los bilbaínos conocían aunque habían permanecido en la sombra en locales conocidos en el barrio de Bilbao la vieja y Cortes.

En la comparsa muchos aseguran actuó por primera vez "La Otxoa", que después se haría tan conocida. La canción que le lanzó a la fama, ese famoso "Libérate" "13, fue el estandarte de la liberación sexual en los años '80.

Sus acciones estaban íntimamente ligadas a lo político aunque no estuvieran afiliados a ningún partido. Lo que hacía única a "La Pinpi" era el hecho de que se aceptara la presencia de todas/os sin importar la etiqueta social, y demostrar que la autogestión sin jerarquías funcionaba.

"Pienso que ese momento fue clave. Era un momento en el que teníamos unas ganas locas de hacer cosas nuevas y donde había un espacio nuevo para realizarlas. Más tarde, probablemente, hubiera habido más cortapisas, más normas" ${ }^{14}$.

\section{Rizoma capitalista}

En Febrero de 2012, un evento extraño dejó al mundo perplejo. Cinco miembros de un grupo de música punk hicieron una actuación en la Catedral de Cristo el Salvador en Moscú. Sus acciones fueron respondidas de inmediato por un grupo de agentes de seguridad. Esa misma tarde las imágenes grabadas de este acontecimiento se convirtieron en un videoclip llamado "Punk Prayer - Mother of God, Chase Putin Away!", traducido, "Una plegaria Punk, Madre de Dios, Echa a Putin de aquí!"15.

Un performance de 40 segundos de duración entre el activismo político y la acción artística, fue planeado y llevado a cabo por un colectivo feminista de arte llamado "Pussy Riot". Vestidas con medias, faldas, camisetas sin mangas de colores, y pasamontañas recortados de colores chillones o "ácidos", gritando enunciados provocativos.

La acción legal que fue llevada a cabo esos días conllevó la detención de tres de las integrantes del colectivo. En un proceso que puso en tela de juicio tanto la vinculación de un estado supuestamente "secular" con la iglesia, a su vez que el derecho a hacer actos de protesta en lugares "santos", lo que desenmascaró fue algo de repercusión mundial.

Definimos esta acción particular con el cuerpo como corte simbólico. Esa catedral era el orden, la norma, la fe, la verdad, las Pussy Riot entraron a romper con ese orden, plantar sobre la mesa la discordia. ¿Qué daño hacían aquellas integrantes? ¿Puede ser que no supieran bien lo que hacían? Implantaron sus significantes, su vestimenta y su música, sus movimientos, en contraste con los de aquellos fieles, sabiendo distorsionarlos, y provocaron una reacción en cadena performativa, activaron los mecanismos de diversos actores sociales y del estado. Un acto simbólico abrupto y cortante puede producir tales repercusiones.

13 Canción: Nielfa, J.A., "La Otxoa", Líbérate, 1978, publicada en 1981.

14 AUTORA (2014) Entrevista a Fernando Toja recogido en el TFM: Acariciar una imagen. Mímesis desviada de la imagen corporal, Universidad del País Vasco, Leioa.

15 LEARNER, Mike; POZDOROVKIN, Maxim (2014) Pussy Riot, Una plegaria punk. 
Acusadas de blasfemia, el acto llegó a occidente en forma de imágenes y artículos de prensa. Su estética atraía a la cultura de masas, incluso a Madonna, la estrella del pop. La presión internacional para que esas tres chicas fueran liberadas, tenía un gran peso sobre el gobierno ruso. Tras haber sido condenadas a 2 años de cárcel, fueron liberadas en 7 meses por las peticiones de amnistía internacional. ¿Qué era lo que producía tan fuerte identificación? En su momento parecía que se habían convertido en ídolos de masas, ¿serían las nuevas "Spice girls"? Madonna quería tocar con ellas en concierto. Aun pensando que la música punk en ruso no llegaría a los estándares de los niveles comerciales, sólo por lo transgresor de sus acciones y estética podían generar un fanatismo mundial.

El revuelo que esta acción produjo fue como el estallido de una bomba colocada en un lugar muy estratégico. La catedral Ortodoxa había sido derribada en el año 1931 por orden de Stalin, para dar lugar al Palacio de los Soviets, que nunca llegó a finalizarse. Los creyentes Ortodoxos habían sufrido la represión estalinista, no pudiendo practicar su fe habiéndose derribado física y simbólicamente su herencia religiosa. En 1988 se creó una organización pública para reconstruir el templo con el apoyo de miembros de la Iglesia Ortodoxa Rusa y con el apoyo del Primer presidente de Rusia, Boris Yeltsin. En el año 1994 comenzó la reconstrucción.

La catedral era la señal de que la tolerancia había llegado a Rusia, y que los habitantes de Moscú no debían temer ser represaliados por sus creencias religiosas. Lo que Pussy Riot quiso criticar no se entendió sino como un ataque que les recordaba una época cuando habían sido vulnerados y marginados por el estado comunista totalitario.

El lazo estrecho entre el ahora presidente de Rusia Vladimir Putin y la iglesia que apoya la discriminación homófoba era lo que realmente criticaba el colectivo feminista. Desde 2007 está prohibida la marcha del orgullo gay. Durante estos años muchos manifestantes han sido encarcelados y juzgados. Las autoridades policiales no han proporcionado protección ante los ataques de extremistas a miembros del colectivo LGTB.

¿Porqué nos sentimos identificados con esta historia tan ajena a nosotros en países del oeste, que vivimos en democracia y supuesta tolerancia hacia la diferencia? El relativismo cultural nos ha llevado a tolerar desde todos los lugares acciones éticamente cuestionables ante los derechos humanos, en el fondo por mantener un estado de equilibrio en la relación globalizada. Esta acción simbólica tocó no sólo temas nacionales, sino uno que nos afecta a todos. Hizo levantarse a la gente ante el conformismo y pensar que tal vez se podían hacer actos que causaran una atención sobre temas tan importantes como la discriminación homófoba.

Puso en cuestión la supuesta democracia en la que convivimos, una continuación del juego entre poderosos ahora conectados por una capitalismo transnacional.

"El filosofo Deleuziano Brian Massumi explica como el capitalismo ya ha sobrepasado la lógica de las normas totalitarias y ha adoptado la lógica del exceso errático. Cuanto más variado, incluso errático, mejor. La normalidad empieza a perder el control. Las regularizaciones empiezan a relajarse. Esta relajación forma parte de la dinámica del capitalismo"16.

16 BERROCAL J., Lee las cartas de Nadezhda Tolokonnikova de Pussy Riot a Slavoj Žižek desde la cárcel, URL: <http://www.playgroundmag.net/musica/noticias-musica/actualidad-musical/lee-las-cartas-de-nadezhdatolokonnikova-de-pussy-riot-a-slavoj-iek-desde-la-carcel->, 16/11/2013 
Esta acción fue clave e irrepetible. Estas acciones no deben tomarse como fórmulas para el cambio, sino como ejemplos de maneras de activarlo. La repetición o reiteración es lo que hay que evitar para no caer en las trampas del aprendizaje mimético.

\section{Identidad Nómada}

\section{El caso de Amina en Femen}

El colectivo Femen fue ampliamente conocido a partir de una noticia de una acción provocativa llevada a cabo en París, en un barrio musulmán. Un grupo de mujeres en topless, con las palabras "musulmán quítate la camiseta" escritas en el pecho en inglés, irrumpían en él muy dispuestas a armar escándalo. Mujeres blancas, con flores en el pelo, el pecho descubierto, gritando y pidiendo la liberación de mujeres de una cultura ajena a la suya. Era evidente que la acción llegaría a los medios y que causaría un revuelo mundial.

En el feminismo relacionado con el islam hay dos tendencias o vertientes principales. Una de ellas condena el islam en su totalidad por ser una religión con una violencia inherente, destructiva hacia colectivos como el de las mujeres, los homosexuales. Un ejemplo de esta mirada es Ayaan Hirsi Ali, mujer de origen Somalí, que encontró asilo en Noruega. Ella escribió "Yo acuso: Defensa de la emancipación de las mujeres musulmanas"17.

Por otro lado, las feministas islámicas, pretenden releer e interpretar el corán para mostrar que la violencia, la opresión, y la incomprensión no son inherentes a la religión, sino interpretaciones subjetivas fabricadas por creyentes radicales sobre ella. Son mujeres que no quieren renunciar a su fe religiosa, mientras buscan maneras de liberarse de las anclas impuestas.

Especialmente en lugares como Irán o Egipto, en el pasado las mujeres han tenido libertad para vestir, para expresarse y para ejercer profesiones por vocación. Las imágenes de Irán en los años '70 antes de la llegada de la revolución islámica son esclarecedoras.

Al oír hablar del caso de Amina Tyler, ex-integrante de Femen, la cuestión se complejiza y aparecen matices. Amina Tyler, tunecina, fue arrestada en Mayo de 2013. Con tan sólo 19 años, estuvo muy decidida a mostrar su cuerpo en fotografías publicadas en internet, con la inscripción en árabe que proclamaba "FUCK YOUR MORALS".

Fue ampliamente criticada por líderes religiosos y políticos que pidieron un castigo corporal ejemplarizante. También recibió numerosas amenazas de muerte. Mientras estuvo encarcelada, la respuesta del colectivo Femen, al que ella apoyaba, fueron una serie de acciones denominadas "Topless Jihad Day"18. Declararon el 4 de Abril el día del Yihad en topless, para que mujeres se retrataran en apoyo a Amina, y acudieran al juzgado en Túnez para apoyarla.

La respuesta no se hizo esperar. Internet permitió la discusión en idas y venidas de imágenes y palabras. Las mujeres feministas islámicas proclamaban no necesitar que las mujeres occidentales blancas vinieran a salvarlas o a imponer sus formas de lucha. El

17 HIRSI ALI, A., (2006); Yo acuso: defensa de la emancipación de las mujeres musulmanas, Galaxia Gutenberg, Barcelona.

18 GORDST, E.,Open letter “topless jihad day”, Huffington Post, <http://www.huffingtonpost.co.uk/2013/04/08/ inna-shevchenko-muslim-women-femens-open-letter-amina-tyler-topless-jihad_n_3035439.html>, 04/04/2013 
cuerpo de una mujer desnuda no era para ellas un símbolo de liberación, sino más bien todo lo contrario, había servido como forma de objetualización sexual en occidente.

Por su parte, la líder del grupo FEMEN ucraniana Inna Shevchenko respondía mediante una carta. "No hay un tipo de derechos humanos para Europeos y otro para Arabes o Americanos, es universal. (...) Entonces, hermanas, (prefiero hablar a las mujeres de todas formas, incluso sabiendo que detrás de ellas hay hombres barbudos con cuchillos). Nos decís que estáis en contra de Femen pero nosotras estamos aquí para vosotras y para todas nosotras, dado que las mujeres son las esclavas modernas y nunca ha sido una cuestión del color de la piel. (...) Decís que vivís tal y como queréis. Siendo la quinta mujer del harem, lo máximo a lo que podéis aspirar es a ser la mujer favorita... ¿verdad?"19.

El colectivo Femen en este caso actúa mediante estereotipos simples que ofenden a las mujeres árabes, una manera de actuar que no tiene en cuenta el contexto. Cuando Amina fue liberada de prisión el 1 de Agosto de 2013, tomó la decisión de abandonar Femen por considerar a la organización islamófoba y sin transparencia económica. Lo primero que hizo al salir fue retratarse en una imagen que ya no la mostraría como parte de Femen, sino como plenamente anarquista.

Tendemos a pensar en un colectivo como un grupo de pensamiento único. Cuando miro las fotos de Amina enseñando el pecho descubierto, veo a una mujer consciente de los usos que se pretenden dar a su cuerpo desde fuera, alguien que está buscando su forma particular la libertad. Tiene cuidado de no reunir los rasgos estereotípicos, defendiendo su diferencia. Femen por el contrario trata a todas las mujeres como iguales, y trata de imponerles una idea universal de libertad. Su estrategia simbólica resulta insuficiente.

Trabajo de creación: EL CUERPO COMO LUGAR DE RESISTENCIA

Algunos de los descendientes de esta cultura empezamos a preguntarnos qué alternativas existen ante un orden simbólico que parecía dirigir hacia destinos fijos e inmutables. Tal vez es porque nuestras identidades se han formado con una variedad inmensa de imágenes de productos de consumo de una sociedad neoliberal capitalista, que nos proporciona la sensación de una libertad ilimitada para ser quienes queramos ser, para saciar nuestra sed, nuestro hambre, nuestro apetito sexual de mil maneras diversas, casi siempre a través de la vista.

Los ejemplos a los que nos hemos referido hasta ahora representan una búsqueda de liberación corporal personal y/o colectiva. Esto que conlleva tanto esfuerzo es también un trabajo bastante eficiente si se planea estratégicamente. El libro llamado "De la dictadura a la democracia"20 de Gene Sharp, propuso más de 198 maneras de luchar con armas no violentas frente a un poder opresor. Entre ellas la mayor parte tienen fuertes componentes simbólicos. Este manual ha llegado a movimientos de liberación tan conocidos como la primavera árabe del 2011.

Tratar de cambiar patrones aprendidos interiorizados supone una gran complejidad. Desviar algo que llega como una vulneración desde el exterior es algo habitual, pero, cómo desviar lo ya interiorizado, ¿como dejar de encarnar una y otra vez las normas del lenguaje y de la imagen?

19 C. NELSON, S., Inna Shevchenko Responds To Muslim Women Against Femen's Open Letter In Wake Of Amina Tyler Topless Jihad, Huffington Post, URL: <http://www.huffingtonpost.co.uk/2013/04/08/inna-shevchenko-muslim-women-femens-open-letter-amina-tyler-topless-jihad_n_3035439.html>, 08/04/2013

20 SHARP, G. (1993); DE LA DICTADURA A LA DEMOCRACIA - Uña Infraestructura Conceptual para la Liberación, Trad. Caridad Inda, La institución Albert Einstein, Boston. 
A través de la creación artística se es capaz de probar los límites, observar como va cambiando el cuerpo y su imagen en el proceso, tratando de encontrar las represiones y censuras que afectan al cuerpo y la identidad propia.

Valorando signos diferentes al símbolo o al icono, la interpretación de la práctica artística se mantiene en cierto modo más abierta. Permite hablar desde lo individual a lo colectivo, sin pretender hacer uso de lo cultural o universal, sino comunicar desde una experiencia parcial y objetiva.

En el proceso creativo el oxímoron sirve no solamente como un recurso para clasificar y encasillar diferentes parámetros de la investigación, sino como material para la creación de piezas que entretejen conceptos opuestos, creando un contraste y un vínculo particular entre ellos. Así, algunas de las obras se titulan en relación a estos juegos retóricos.

\section{Histeria bella}

Cierra los ojos ${ }^{21}$, Raquel Asensi, Piezas de loza vidriada y globos de latex, 2014

Esta pieza nace del deseo de cerrar los ojos ante la glotonería incontenible de las imágenes y cultivar más otros sentidos, como el tacto. Estamos en contacto constante con muchos tipos de imágenes corporales que tratan de identificarnos y proponernos una manera particular de estar en el mundo. Cultivar más otro tipo de sentidos y valorar otros tipos de hábitos corporales nos ayuda a salir del aprendizaje mimético.

\section{Coraza frágil}

KISS ME, La coraza ${ }^{22}$, Raquel Asensi, Loza vidriada, maniquí, lana. 2015

La ropa nos protege no sólo del frío, sino de los factores sociales, proporcionándonos una imagen identitaria con la que pasar desapercibidos, camuflados, o con la que podemos ser también llamativos, y romper con el orden cotidiano. Romper con esta imagen cotidiana puede significar adquirir una apariencia agresiva o punzante.

Esta pieza es una prenda de vestir realizada en cerámica vidriada blanca, a partir de moldes de pepinos orgánicos punzantes, tejidos entre sí con la técnica del ganchillo y lana blanca. Esta pieza reúne conceptos opuestos, ya que es una pieza que connota aspectos de protección, fragilidad y agresividad. Aúna lo extraño y lo familiar, dando lugar a una experiencia relacionada con lo siniestro. Desde una percepción táctil es suave y cálida, a la vez fría y punzante.

\section{Identidad nómada}

SER OTRO23, Raquel Asensi, Loza con terra sigilatta, 2015.

21 Pieza artística: ASENSI, Raquel, Cierra los ojos, 2014, URL: <https://raquelasensi.es/2016/02/06/504/> $06 / 02 / 2016$

22 Pieza artística: ASENSI, Raquel, KISS ME, La coraza, 2014, URL: $<\underline{\text { https://raquelasensi.es/2016/02/06/507/> }}$ $06 / 02 / 2016$

23 Pieza artística: ASENSI, Raquel, SER OTRO, 2014, URL: < $\underline{\text { https://raquelasensi.es/2016/02/06/553/> }}$ $06 / 02 / 2016$ 
Dos piezas hechas de loza con terra sigilatta atadas al cuerpo con un cordel dorado, huellas del torso de dos personas de distinto sexo, prótesis intercambiables que permiten imaginar ser otro. Corazas frágiles que hablan de identidades que no se mantienen fijas, sino que cambian incesantemente. Esta pieza juega a romper con la imitación corporal a través del intercambio de significantes de género; indumentaria, ropa, extensiones del cuerpo.

\section{Conclusiones}

"El arte no es un espejo que refleje el mundo, sino un martillo para darle forma." ${ }^{24}$

¿Qué alternativas artísticas y/o sociales existen como respuesta al poder biopolítico ejercido sobre los cuerpos? ¿Es posible ejercer un cambio personal o social mediante la acción relacionada con el cuerpo? ¿Cuales son las normas culturales inscritas en el cuerpo? ¿Qué constituye a los cuerpos como agentes? ¿Cómo se produce la conversación entre las imágenes corporales y/o los cuerpos?

Las preguntas, la hipótesis, las reflexiones a partir de la teoría, el análisis de los casos analizados y la creación, se convierten a través del oxímoron en un trabajo común, inseparable, donde el conocimiento se genera desde distintos puntos de vista o miradas que convergen. Se genera un conocimiento en el que las conclusiones no son fijas, sino abiertas.

Existen y confluyen hoy en día diversas estrategias simbólicas que utilizan los agentesintérpretes a través de la acción corporal para generar atención sobre asuntos que atañen a individuos y colectivos. A través de la comunicación veloz por internet, la democratización de los medios, y la posibilidad de la reproductibilidad técnica, se han generado diversos tipos de prácticas subversivas corporales que pretenden hacer frente a un poder que se inmiscuye en todos los aspectos de la vida privada y pública.

A través del análisis de algunos casos podríamos decir que una de las estrategias más habituales es la producción de cortes simbólicos en lugares estratégicos, como es el caso de Pussy Riot o el de Amina en Femen. Consideramos de gran importancia comprender el contexto cultural y social donde se realizan estas acciones para que sus efectos performativos sean constructivos.

Otra estrategia utilizada se basa en mostrar imágenes del cuerpo e identidades habitualmente escondidas o veladas ya existentes, para normalizarlas, como es el caso de la comparsa Pinpilinpauxa en la ciudad de Bilbao. Los significantes utilizados para la normalización de cuerpos e identidades disidentes requieren connotaciones que promuevan la aceptación del contexto donde se originan. En el caso de la comparsa, promoviendo signos de elegancia, intelectualidad, y libertad sexual.

Los trabajos de creación creados durante el proceso de investigación han sido influenciados por las dos estrategias; generando cortes simbólicos en el ámbito artístico y revalorizando imágenes del cuerpo anteriormente veladas. La tradición artística en muchos casos reafirma las fantasías de poder a través de paradigmas como la originalidad, la creatividad, la objetividad, la estabilidad y unicidad. En los trabajos de creación ha sido importante

24 BRECHT, B. (1934); Las cinco dificultades para decir la verdad, Biblioteca virtual móvil de las juventudes comunistas, URL: <http://archivo.juventudes.org/textos/Bertold\%20Brecht/Las $\% 20$ cinco $\% 20$ dificultades $\% 20$ para $\% 20$ decir $\% 201 \mathrm{a} \% 20$ verdad.pdf $>$ 
generar vínculos a través de procesos intuitivos y complejos, reemplazando la estabilidad con lo cambiante, la singularidad con la multiplicidad, y la separación con la transgresión.

\section{Bibliografía}

Libros

A. LARUMBE GURRAITZ, M. A. (1976-1979); VINDICACIÓN FEMINISTA: Una voz colectiva, una historia propia. Antología facsímil de textos, Prensa Universitaria de Zaragoza. AUSTIN, J.L. (1955); Como hacer cosas con palabras, Edición electrónica. URL: <www.philosophia.cl/> Escuela de Filosofía Universidad ARCIS. BRECHT, B. (1934); Las cinco dificultades para decir la verdad, Biblioteca virtual móvil de las juventudes comunistas, URL: <http://archivo.juventudes.org/textos/Bertold $\% 20$ Brecht/Las\%20cinco\%20dificultades\%20para\%20decir\%20la\%20verdad.pdf $>$ BUTLER, J. (2004); Lenguaje, poder e identidad, Vallehermoso, Síntesis S.A. DELEUZE, Gilles; GUATTARI, Félix (2013); RIZOMA Introducción, trad. José Vazquez Pérez y Umbelina Larraceleta, Valencia, pp. 17-28. Ed. original: (1977) Rhizome (Introduction), Editions de Minuit, París. FOUCAULT, M. (2005); Historia de la sexualidad 1. La voluntad de saber, trad. Ulises Guiñazú, Madrid, Siglo XXI DE ESPAÑA EDITORES, Ed. original: (1976) Histoire de la sexualité. 1. La volonté de savoir, Editions Gallimard, Paris. GEERTZ, Clifford (1994); Conocimiento local, Paidós ibérica S.A., Barcelona, Ed. original: (1983) Local Knowledge,, Further essays in interpretative anthropology. Basic Books Inc. HIRSI ALI, A. (2006); Yo acuso: defensa de la emancipación de las mujeres musulmanas, Galaxia Gutenberg, Barcelona, IRIGARAY L. (2007); Espéculo de la otra mujer, Ediciones Akal, S.A., Madrid. Ed. original: (1974) Speculum de l'autre femme, Les Éditions de Minuit, París. J. HARAWAY, D. (1995); Ciencia, cyborgs y mujeres, Ediciones Cátedra S.A., Madrid. Ed. original: (1991) Simians, Cyborgs and Women. The Reinvention of Nature, Free Asociation Books, Ltd., London LACAN, J., (1972-1973); Los Seminarios de Jacques Lacan / Seminario 20. Aún (08/08/2015) Edición electrónica, URL: <https://agapepsicoanalitico.files. wordpress.com/> SHARP, G. (1993); DE LA DICTADURA A LA DEMOCRACIA - Una Infraestructura Conceptual para la Liberación, Trad. Caridad Inda, La institución Albert Einstein, Boston.

Artículos web

C. NELSON, S., Inna Shevchenko Responds To Muslim Women Against Femen's Open Letter In Wake Of Amina Tyler Topless Jihad, Huffington Post, URL: <http://www. huffingtonpost.co.uk/2013/04/08/inna-shevchenko-muslim-women-femens-open-letteramina-tyler-topless-jihad_n_3035439.html>, 08/04/2013

BERROCAL, J., Lee las cartas de Nadezhda Tolokonnikova de Pussy Riot a Slavoj Žižek desde la cárcel, URL: <http://www.playgroundmag.net/musica/noticias-musica/actualidad-musical/lee-las-cartas-de-nadezhda-tolokonnikova-de-pussy-riot-a-slavoj-iek-desdela-carcel->, 16/11/2013 
GORDST, E., Open letter “topless jihad day”, Huffington Post, <http://www.huffingtonpost.co.uk/2013/04/08/inna-shevchenko-muslim-women-femens-open-letter-aminatyler-topless- jihad_n_3035439.html>,04/04/2013

LACOMUNA, La ley de peligrosidad social y la represión franquista, URL: <http://www. lacomunapresxsdelfranquismo.org/2012/02/08/la-ley-de-peligrosidad-social-y-la-represion-franquista/>, 08/02/2012

Audiovisual:

LEARNER, Mike; POZDOROVKIN, Maxim (2014); Pussy Riot, Una plegaria punk

CALDERON, P. (2003); Foucault par lui-meme

Otros:

ASENSI BLANCO, R. (2014): Acariciar una imagen. Mímesis desviada de la imagen corporal, (Entrevista a Fernando Toja recogido en el TFM), Universidad del País Vasco, Leioa· www.raquelasensi.es/ 